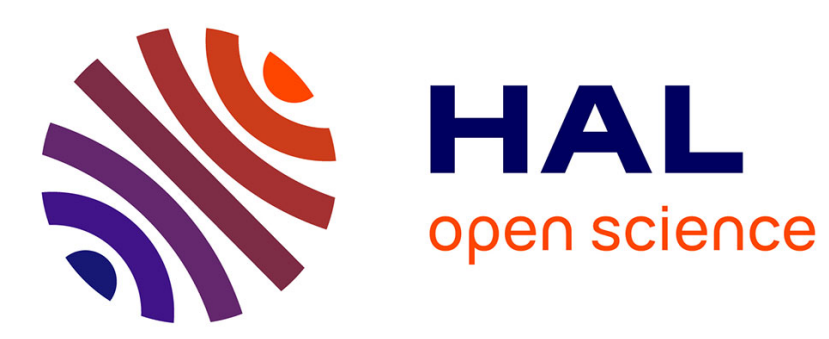

\title{
Internal Friction Studies in NixZn1-xFe2O4 Films
}

S. Murthy

\section{- To cite this version:}

S. Murthy. Internal Friction Studies in NixZn1-xFe2O4 Films. Journal de Physique IV Proceedings, 1997, 07 (C1), pp.C1-489-C1-490. 10.1051/jp4:19971199 . jpa-00254849

\section{HAL Id: jpa-00254849 https://hal.science/jpa-00254849}

Submitted on 1 Jan 1997

HAL is a multi-disciplinary open access archive for the deposit and dissemination of scientific research documents, whether they are published or not. The documents may come from teaching and research institutions in France or abroad, or from public or private research centers.
L'archive ouverte pluridisciplinaire HAL, est destinée au dépôt et à la diffusion de documents scientifiques de niveau recherche, publiés ou non, émanant des établissements d'enseignement et de recherche français ou étrangers, des laboratoires publics ou privés. 


\title{
Internal Friction Studies in $\mathrm{Ni}_{x} \mathrm{Zn}_{1-x} \mathrm{Fe}_{2} \mathrm{O}_{4}$ Films
}

\author{
S.R. Murthy \\ Department of Physics, Osmania University, Hyderabad 500 007, India
}

\begin{abstract}
Internal friction in polycrystalline $\left(\mathrm{Ni}_{\mathrm{x}} \mathrm{Zn}_{1-\mathrm{x}}\right) \mathrm{Fe}_{2} \mathrm{O}_{4}($ where $\mathrm{x}=0.2,0.6$ and 0.8 ) films has been measured using one crystal composite oscillator method. The internal friction was recorded at three different frequencies i.e, 60,100 and $160 \mathrm{KHz}$ in the temperature range of 80 to $600 \mathrm{~K}$. The films used are prepared by tf-sputtering method on quartz plate substate. $\mathrm{X}$-ray analysis was carried out on the as prepared and annealed films to check the crystallization. $\mathrm{MH}$ curves at room temperature are observed using a VSM up to a magnetic field of $20 \mathrm{kOe}$. It was found that the results of X-ray diffraction and saturation magnetization are consistent each other. It was also found that the values of initial permeability in the frequency range of $1 \mathrm{MHz}-600 \mathrm{MHz}$ are better than those of bulk materials. In all samples under investigation the internal friction with temperature three peaks at 580,510 and $280 \mathrm{~K}$. The observed peaks and other results are compared with magnetic properties and available domain theories.
\end{abstract}

\section{INTRODUCTION}

$\mathrm{Ni}-\mathrm{Zn}$ ferrites are considered as the substances which are suitable for the devices used in the high frequency applications, because of their resistivity is very high. Therefore many studies are undertaken on the bulk materials. However, there is very less information on the thin films of $\mathrm{Ni}-\mathrm{Zn}$ ferrites, hence we report on the resuits of the preparation of Ni-Zn ferrite thin films by rf - sputtering. As a part of our programme on investigation of domain wall dynamics in ferrimagnetic oxides, internal friction studies are conducted using the one crystal composite oscillator method in the temperature of 80-600 K.

\section{EXPERIMENTAL}

The Ni-Zn ferrites films with formula $\mathrm{Ni}_{\mathrm{x}} \mathrm{Zn}_{1-\mathrm{x}} \mathrm{Fe}_{2} \mathrm{O}_{4}(\mathrm{x}=0.2,0.6$ and 0.8$)$ about $60 \mathrm{~nm}$ to $1.2 \mu \mathrm{m}$ thick were been prepared by rf-sputtering apparatus. The quartz glass plate of $2.5 \mathrm{~mm}$ thick was selected as substrate. The background vacuum was about $10^{-6}$ Torr before discharge. The flow meters are used to control the flow rate of argon and oxygen gases. The power supply between the target and the substrate amounted to $10 \mathrm{~W} / \mathrm{cm}^{2}$. X-ray analysis was carried out on the prepared and annealed films to check the crystallization. It was found that the films are of a random polcrystalline $\mathrm{Ni}-\mathrm{Zn}$ ferrites. The mean grain size and surface roughness have been measured by using an atomic force microscope and it was found that the average thickness for all films is $1 \mu \mathrm{m}$, the mean grain size is $540 \mathrm{~nm}$ and surface roughness is $80 \mathrm{~nm}$. Many more results about preparation of films are given in our earlier communication [ 1$]$.

The magnetic properties were measured by using a VSM up to a maximum field of $20 \mathrm{kOe}$. The initial relative permeability was measured in the frequency range of $1-600 \mathrm{MHz}$ using a impedance analyzer at room temperature.

A one crystal piezoelectric composite osillator was used to measure the internal friction in the thin films. The major disadvantage of composite oscillator methods [ 2 ] was that it is not possible to determine the internal friction on the solids at different frequencies. The present exprimental setup consists of one quartz crystal in the place of two crystals. Hence, the cost of the oscillatory system decreases; errors occuring to bonding are 
lower and the mechanical rigidity is better. A $20 \mathrm{kHz}$ quartz crystal of length ( L ) with gaps of eltrodes at $\mathrm{L} / 2, \mathrm{~L} / 4$. and $\mathrm{L} / 8$ yielding frequencies 40.80 and $160 \mathrm{kHz}$. have been used in the present investigation. The accuracy of measurements of internal friction is about $+/-2 \%$.

\section{RESULTS AND DISCUSSION}

The Fig. I gives typical $\mathrm{MH}$ curve obtained for the $\mathrm{Ni}_{0.4} \mathrm{Zn}_{0.6} \mathrm{Fe}_{2} \mathrm{O}_{4}$ film. It was found that the saturation magnetization values are consistent with the results of X-ray diffraction. It can be seen from Fig. 2 that the real part of permeability is independent of froquency in the range of $1-600 \mathrm{MHz}$. The magnitude of the initial permeability for the all the films is in the range of 30 to 60 . Thus. the observed frequency characteristics for these films are better than bulk materials. It can be seen from the Fig. 3 that the variation of $Q^{1}$ versus temperature $\mathrm{T}$, for one of the typical $\mathrm{Ni}_{0.4} \mathrm{Zn}_{0.6} \mathrm{Fe}_{2} \mathrm{O}_{4}$ film at three frequencies i.e. 40.80 and $160 \mathrm{kHz}$. It can be seen from the figure that the thermal variations of interal friction are similar: however. the magnitude are different. It can be seen from the figure that the variation of $Q^{-1}$ versus $T$ shows three peaks at 580,510 , and $280 \mathrm{~K}$. The peak obseried at $580 \mathrm{~K}$ disappeared when we applied a magnetic field equal to the saturation field of the sample under investigation i.e.. $2000 \mathrm{Oe}$. It was also found that the peaks observed at 510 and $280 \mathrm{~K}$ are found to be independent of the applied magnetic field. Similar results are observed in all other films.

The peak observed at $580 \mathrm{~K}$ is found to be near the Curie temperature of the sample i.e.. $585^{\circ} \mathrm{C}$ and therefore it is due to domain walls. This is because. this peak was absent in the single domain state of the sample and present only in the multidomain state. The occurence of this peak can be theoretically explained by statistical theory of ferromagnetic domain walls given by Landau ( 3 l. According to this theory: the domain wall energy changes periodically with the variation of its position. There exists a barrier which obstructs the motion of the domain walls and which inturn decreases their mobility. As the tenperature increases and approches $T_{c}$. the domain wall width increases as $1 /\left(T_{c}-T\right.$ ) and results in the exponential decrease of barriers and causes an infinite increase of mobility of domain walls. There may be a greater number of domains which appear abruptly when passing through the Curie point and then these domains slowly coagulate into larger ones. In other words. the density of the domain walls increases when the temperature approaches Curie point.

Acknowledgements: I thank Dr.M.Guyot and V.Cagan. CNRS. Laboratoire de Magnétisme et d'Optique de l' Université de Versailles, France, for giving target ferrite materials.

Refrences:

1.S.R.Murthy, J.A.S.I., 10, 45 ( 1993 )

2. S.R.Murtly and Nagalaxmi, J.A.S.I., 12. 15 ( 1995 ).

3. L.D.Landau and E.M.Lifsshitz, Stastical Physics, ( Pergamon Press, London ) p398 (1959).

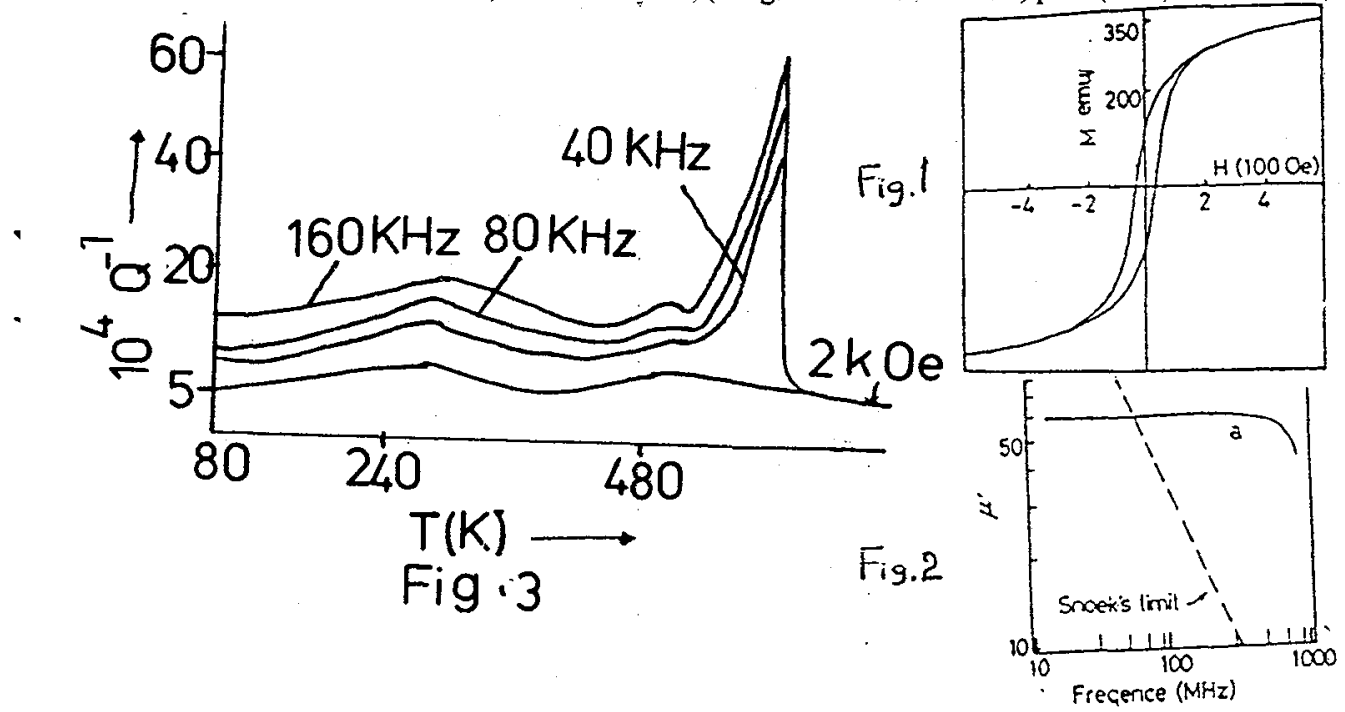

